\title{
Circadian Sleep Disruption and Cancer Risk
}

\author{
S.-Hakki Onen ${ }^{1,2}$ and Fannie Onen $3,4,5$ \\ ${ }^{1}$ Sleep Medicine Center, Croix Rousse University Hospital, Hospices Civils de Lyon, Lyon, France \\ ${ }^{2}$ Institut National de la Santé et de la Recherche Médicale U-1028, University of Lyon, Lyon, France \\ ${ }^{3}$ Bichat University Hospital, Assistance Public des Hôpitaux de Paris, Geriatrics and Sleep Medicine Clinics, Paris, France \\ ${ }^{4}$ Centre de Recherché en Epidémiologie et Santé des Populations \& Institut National de la Santé et de la Recherche Médicale U-1178, \\ University of Paris, Paris, France \\ ${ }^{5}$ Center for Sleep and Circadian Neurobiology, University of Pennsylvania, Philadelphia, PA, USA
}

In modern societies, circadian sleep disruption is a major consequence of both night shift work, and chronic exposure to artificial light at night (LAN) and has been shown to lead to increased likelihood of hormone-dependent cancers including breast and prostate in several cohort and case-control studies as well as in animal experiments. In addition, strong mechanistic evidence has been reported at the cellular and molecular levels in this regard. Thus, in the monographs of carcinogenic hazards to humans, the International Agency for Research on Cancer (IARC) classified shift work that involves circadian disruption in Group 2A, 'probably carcinogenic to humans' consecutively in 2007 and in 2019. This review aims to enable a better understanding of the complex relationship between circadian sleep distribution and cancer risk and addresses some precautionary measures to limit the risk of carcinogenesis in populations working in night-shifts and/or exposed to LAN.

Key Words: Circadian disruption; Cancer; Sleep; Shift work; Light at night

Received: November 4, 2019 Accepted: December 6, 2019

Corresponding author: S.-Hakki Onen, MD, PhD, Sleep Medicine Center, Croix Rousse University Hospital, 103 Grande Rue de la Croix Rousse, 69004 Lyon, France. Tel: 33-472-071-929, Fax: 33-472-072-808, E-mail: saban-hakki.onen@chu-lyon.fr

@ This is an Open Access article distributed under the terms of the Creative Commons Attribution Non-Commercial License (https://creativecommons.org/licenses/by$\mathrm{nc/4.0)}$ which permits unrestricted non-commercial use, distribution, and reproduction in any medium, provided the original work is properly cited.

\section{INTRODUCTION}

Cycles of sleep and wake occur within a circadian chronobiological context. Exposure to sunlight during the day and darkness at night optimally entrains sleep-wake and other biological rhythms to promote homeostasis and human health. Environmental light synchronizes the master circadian pacemaker in the suprachiasmatic nuclei (SCN) of the hypothalamus, as well as many peripheral clocks in tissues and cells, to the solar 24-hour day. Circadian sleep disruption is common in industrialized societies as a result of night shift work, repeated transmeridian flights and mistimed sleep and has been linked to a number of pathological conditions, including hormone-dependent cancers.

On the basis of limited human evidence and sufficient evidence in experimental animals, in 2007 a Working Group from the International Agency for Research on Cancer (IARC) based in Lyon, France classified 'shift work that involves circadian disruption' as 'probably carcinogenic to humans,' Group 2A [1]. In other words, the IARC which is part of the World Health Organization (WHO), placed shift work in the same category as occupational exposures in petroleum refining and chronic infection with hepatitis $\mathrm{C}$ virus in terms of cancer risk (Table 1) [2]. Thus, in 2009, Denmark has become the first country to pay government compensation to women who developed breast cancer after long spells of working at night [3].

Recently, in June, 2019, using the new and updated data, the IARC finalized its evaluation of the carcinogenicity of shift work. Again, the IARC Working Group classified shift work in Group $2 \mathrm{~A}$, 'probably carcinogenic to humans', based on limited evidence of cancer in humans and sufficient evidence of cancer as well as strong mechanistic evidence in experimental animals [4].

This review aims to enable a better understanding of the complex relationship between circadian sleep distribution and cancer risk. We first briefly present possible cellular and neuro-endocrine mechanisms involved in this relationship. We then highlight epidemiological data supporting the potential for circadian sleep distribution to act as a carcinogenic agent in the development of hormone-dependent breast and prostate cancers. Finally we address some precautionary measures to limit the risk of carcinogenesis in populations exposed to light at night (LAN). 
Table 1. IARC-WHO identification of carcinogenic hazards to humans

\begin{tabular}{llc} 
Group & \multicolumn{1}{c}{ Grade } & Agents, examples \\
1 & Carcinogenic to humans & 120 agents : arsenic and inorganic arsenic compounds , painter (occupational \\
& & exposure as a), estrogen-progestogen oral contraceptives (combined)
\end{tabular}

Based on the evidence available, the IARC-WHO grades potential cancer-causing hazards, and then groups them accordingly. National health agencies can use this information as scientific support for their actions to prevent exposure to potential carcinogens.

IARC: International Agency for Research on Cancer, WHO: World Health Organization.

Adapted from https://monographs.iarc.fr/agents-classified-by-the-iarc/ [2].

\section{CELLULAR AND NEURO-ENDOCRINE MECHANISMS OF CIRCADIAN DISRUPTION AND CARCINOGENESIS}

The dominant environmental factor that can reset and thereby disrupt the circadian rhythm is LAN [5]. Chronic exposure to LAN and behavioral disruptions to circadian rhythms (i.e., repeated transmeridian flights, night or rotating shift work, or mistimed sleep) result in a desynchronisation of the master circadian pacemaker with many self-sustained and autonomous peripheral oscillators in tissues and cells [6].

This internal desynchrony between the master circadian pacemaker in the SCN and peripheral oscillators is hypothesized to increase cancer risk through at least three related pathways: 1) direct disruption of the circadian clock genes function that control cell proliferation, 2) nocturnal suppression of the pineal hormone melatonin, and 3) dysregulation of circadian cortisol rhythm.

\section{Circadian clock genes and carcinogenesis}

Around a dozen of circadian clock genes (peripheral oscillators) regulate cell proliferation and apoptosis at multiple sites. Dysregulation in clock gene expression is associated with the risk of developing cancers by impacting on the biological pathways that regulate DNA damage and repair, carcinogen metabolism, cell-cycle and apoptosis [6]. Structural variations in the circadian gene PER3 and non-synonymous polymorphisms in the circadian gene NPAS2 were detected to be significantly associated with increased risk of breast cancer, especially among younger women $[7,8]$. In addition, variations in core circadian gene cryptochrome 2 (CRY2) is known to increase both risk of developing non-Hodgkin's lymphoma and prostate cancer risk [9]. In contrast, some polymorphisms in NPAS2 appeared to be protective against these malignancies [10].

Nocturnal melatonin suppression by light as a cancer risk factor

Melatonin produced by pineal gland at night is the biochemical correlate of darkness and may impact initiation, promotion and progression of tumor growth. Chronic exposure to artificial LAN results in a significant decrease in melatonin release, and appears to cause tumor development in endocrine target tissues at least by two mechanisms including dysregulaion in sexual hormones synthesis and increase in oxidative stress at the cellular level [11].

In experimental models, suppression of melatonin via constant light exposure or pinealectomy augments levels of estrogens and androgens and contributes to increase the incidence of breast and prostate malignancies in a dose dependent manner [11]. In contrast, increased melatonin levels have been shown to inhibit or to slow down tumor growth both in vitro and in vivo, including breast $[12,13]$ and prostate cancers [14].

Melatonin, an effective antioxidant may limit the initiation of cancer by protecting cells from severe DNA damage that is consequence of unstable oxygen-derived and nitrogen-derived toxic reactants (free radicals) [15]. Melatonin and its metabolites act both directly by scavenging free-radicals [15] and indirectly by stimulating antioxidative enzymes [16], which metabolize the toxic compounds to innocuous metabolites. In addition to protecting DNA from destructive oxidant carcinogens, melatonin may also enhance DNA repair capacity by affecting several key genes involved in DNA damage responsive pathways [17].

\section{Dysregulation of circadian cortisol rhythm as a cancer} risk factor

Cortisol level is regulated via the hypothalamic-pituitary-adrenal (HPA) axis and shows a strong circadian rhythm with a peak in the morning, 30-45 min after first awakening and a nadir during sleep [18]. Insults to the circadian system (i.e., chronic sleep deprivation and shift work) may alter the response of the HPA axis to the circadian cues responsible for the physiologic pattern of the diurnal cortisol curve [19]. Poorly coordinated cortisol levels with permanent flattened diurnal profile and circadian restactivity rhythms have been linked with advancing cancer and accelerated tumor growth rates $[20,21]$ as well as increased risk of mortality in metastatic breast cancers [22]. 
Cortisol would act by stimulating the P450 aromatase activity, which is involved in the conversion of adrenal androgens to estrogens in adipose tissue and muscle [23,24]. It has been suggested that increased aromatase activity leads to increased breast and prostate cancer risks $[23,25]$. Due to the natural involvement of cortisol in the functioning of the prostate and mammary glands, its circadian dysregulation and prolonged diurnal presence in blood and tissues is likely to expose prostate and breast cells to the activation of downstream biological pathways outside their normal context [26].

\section{EPIDEMIOLOGICAL EVIDENCES}

Epidemiological data on hormone-dependent breast and prostate cancer risks linked to disturbances of the circadian sleep rhythm can be analyzed from both night shift work and habitual sleep duration perspectives.

\section{Breast cancer}

Breast cancer is the most commonly occurring cancer in women worldwide, with the highest rates found in the Western Europe, Australia and North America [27]. Breast cancer risk is affected by a combination of several factors including genetic predisposition, advanced age, lifetime exposure of breast tissue to hormones (early menarche, late menopause, and hormone use) and lifestyle choices [28]. Modern lifestyle and consequent exposure to artificial LAN also have been reported as a possible risk factor for breast cancer $[29,30]$. Furthermore, migrant studies have shown that, over successive generations, incidence rates increase in women who migrate from low-incidence countries in Asia and Latin America to high-incidence countries, such as the United States and Australia, approaching the incidence rates observed in the host country [31-33].

\section{Shift work and breast cancer}

The association between an increased risk of breast cancer and night shift work has been reported by numerous epidemiologic studies, including cohort studies, case-control studies, and metaanalysis [34-40]. The risk of breast cancer seems to be linked to the nature and exposure metrics of night shifts. For some authors, regardless of years of exposition, there is some evidence that high number of consecutive night shifts has impact on the extent of circadian disruption, and thereby increased breast cancer risk. For others, there is a dose-response relationship between years of night shift work exposition and breast cancer risk. In a cohort study of 102,869 women aged 16 or older from the UK during a 9.5-year median follow-up period, there was a significant link between raised breast cancer risk and average hours of night work per week ( $p=0.035$ ) [40]. A Norwegian cohort of 43,316 nurses has also reported a significant increase in the risk among nurses who worked at least 5 years performing at least 6 consecutive night shifts per month [odds ratio (OR): 1.8, 95\% confidence interval (CI): 1.1-2.8] [38]. These results suggest that the risk of breast cancer may be related to number of consecutive night shifts. A dose-response relationship between rotating night shift work and breast cancer has emerged in the US based Nurse Health Study [34]. This prospective cohort involved 78,562 nurses who had worked at least three nights per month and followed over a 10 -year period. Authors have reported a significant increase in breast cancer risk among the women who worked 30 or more years on rotating night shifts indicating a multivariate adjusted relative risk (RR) of 1.36 (95\% CI: 1.04-1.78) [34]. In an additional study, same authors followed 115,022 nurses over a period of 12 years. Breast cancer was diagnosed in 1,352 of them. The RR for breast cancer was 1.79 (95\% CI: 1.06-3.01) for women who worked at least 3 night shifts per month over a period of 20 years [35]. In contrast, a meta-analysis including 10 prospective studies concluded that night shift work for 20 or more years has little or no effect on breast cancer incidence [41]. However, several shortcomings with this meta-analysis have been underlined: 1) exclusion of all retrospective studies as uninformative, 2) inclusion of studies where the assessment of shift work fell below the IARC working group standards, 3) assessment of shift work often based on selfreport (and so was not collected prospectively), and 4) the heterogeneity in definitions of shift work that contraindicate the data being combined in a meta-analysis [42]. Based on a comparative case-control study of 1,679 Israeli women, exposure to LAN in the "sleeping habitat" has been found to be associated with breast cancer risk (OR: 1.22, 95\% CI: 1.11-1.31; p<0.001) [43]. Authors concluded that, not only should artificial light exposure in the working environment be considered as a potential risk factor for breast cancer, but also LAN in the "sleeping habitat."

\section{Sleep duration and breast cancer}

Several observational studies have investigated the association between sleep duration and breast cancer risk with conflicting results: 1) short sleep duration might increase the risk and longer sleep duration might decrease this risk, 2) longer sleep duration might increase the risk, 3) sleep duration has no impact on the risk, 4) sleep duration might have a U shaped impact on the risk.

First, a significant number of population-based observational studies reported that short sleep duration is associated with an increased risk [44,45], or aggressiveness [46], and longer sleep duration with a decreased risk of breast cancer $[47,48]$. In the Ohsaki Cohort Study of 23,995 Japanese women, participants who slept 6 hours or less compared to a reference group of women who slept 7 hours were more likely to have a breast cancer with a multivariate hazard ratio (HR) of 1.62 (95\% CI: 1.05-2.50; $\mathrm{p}$ for trend= 0.03) [44]. Later, the Southern Community Cohort Study carried out to investigate the role of sleep duration in breast cancer among African American women found results similar to those observed in Japanese females. Compared to the reference group with an average sleep of 8 hours per day, black women with shorter sleep had an increased risk of hormone receptor negative breast cancer [ORs (95\% CIs): 2.13 (1.15-3.93), 1.66 (0.92-3.02) and 2.22 (1.19-4.12) for $<6,6$ and 7 hours, respectively, $\mathrm{p}$ for trend, 0.04] 
[45]. Thompson and Li [46] have investigated habitual sleep duration and likelihood of cancer recurrence (aggressiveness) of 101 early stage estrogen receptor positive (ER+) breast cancer patients. Authors found that cancer recurrence scores were strongly correlated with average hours of sleep per night before breast cancer diagnosis, with fewer hours of sleep associated with a higher (worse) recurrence score $(\mathrm{r}=-0.30, \mathrm{p}=0.0031)$. This correlation was limited to post-menopausal breast cancer patients only ( $\mathrm{r}=-0.41, \mathrm{p}=0.0011$, for postmenopausal patients; $\mathrm{r}=-0.05$, $\mathrm{p}=0.80$, for premenopausal patients). This association remains statistically significant after adjustment for age, physical activity, smoking status, and body mass index in the entire study sample $(\mathrm{p}=0.0058)$ as well as in postmenopausal patients $(\mathrm{p}=0.0021)$. Verkasalo et al. [47] investigated the association between longer sleep duration and lower breast cancer risk in the Finnish Twin Cohort study. In addition, authors explored the relations of insufficient sleep and sleep quality with breast cancer. Analysis restricted to the 7,396 women (146 cases of breast cancer) whose sleep duration during a 6-year period was stable. After adjustment for confounding risk factors, The HRs for breast cancer in the short ( $\leq 6$ hours), average (7-8 hours), and long sleep ( $\geq 9$ hours) duration groups were 1.10 (95\% CI, 0.59-2.05), 1.0, and 0.28 (95\% CI, 0.09-0.88), respectively. A significantly lower risk $(\mathrm{p}=0.03)$ in women who reported a long duration of sleep ( $\geq 9$ hours per night) compared with the average duration of 7 or 8 hours was observed. No statistically significant effects were observed for sleep insufficiency and sleep quality. Wu et al. [48] investigated the relationship between self-reported usual sleep duration determined at baseline and subsequent risk of breast cancer in the prospective, population-based cohort of the Singapore Chinese Health Study. During the follow-up period (up to 11 years), 525 incident breast cancer were identified among 33,528 women participating in the study. Among women postmenopausal at baseline, breast cancer risk decreased with increasing sleep duration $(\mathrm{p}=0.047)$. Women who reported $\geq 9$ hours of sleep per night showed an RR of 0.67 (95\% CI: 0.4-1.1) compared with those who reported $\leq 6$ hours of sleep per night.

Second, only a few studies have stated that longer sleep duration may increase the risk of breast cancer. One case-control study from the US [49], including premenopausal and postmenopausal breast cancers, found that self-reported longer sleep duration in the past 2 years slightly increased the risk of breast cancer ( 9 or more versus 7-8 hours of sleep per night). The multivariate-adjusted OR for developing breast cancer was 1.06 (95\% CI: 1.011.11 ), suggesting a $6 \%$ increase in risk for every additional hour of sleep. According to a more recent meta-analysis based on 10 studies involving 415,865 participants; compared to women with the reference number of sleep hours (6 to 7 hours), women with a longer sleep duration might have a significantly increased risk of breast cancer, especially estrogen receptor-positive breast cancer ( $p$ for trend $=0.024$ ) [50].

Third, in some other studies, no association was observed for shorter or longer sleep duration. Vogtmann et al. [51] investigated the Women's Health Initiative (WHI) consisted of four clinical trials and one observational study to determine whether the duration of sleep, sleep quality, insomnia, or sleep disturbance was associated with incident breast cancer. A total of 5,149 incident cases of breast cancer were identified in this study. No statistically significant associations were found between self-reported sleep duration, sleep quality, insomnia, or level of sleep disturbance with the risk of breast cancer after multivariable adjustment. Pinheiro et al. [52], explored the association between habitual sleep duration and risk of breast cancer in the Nurses' Health Study including 77,418 women. During 16 years of follow-up, 4,223 incident cases of breast cancer occurred. Compared with women sleeping 7 hours, covariate-adjusted HRs and 95\% CIs for those sleeping 5 or less, 6,8 , and 9 or more hours were 0.93 (0.79-1.09), 0.98 (0.91-1.06), 1.05 (0.97-1.13), and 0.95 (0.82-1.11), respectively. In conclusion, authors found no convincing evidence for an association between self-reported sleep duration and the incidence of breast cancer.

Fourth, a population-based case-control study from Guangzhou, China indicates a $\mathrm{U}$ shaped relationship between sleep duration and breast cancer [53]. Wang et al. [53] conducted face-toface interviews with 712 women diagnosed with incident invasive breast cancer before treatment and 742 age-matched controls. Among all subjects, $33.0 \%$ of cases and $26.2 \%$ of controls reported ever having night-shift work [OR (95\% CI): 1.34 $(1.05-1.72)]$. Compared to women with an average sleep duration (6.1-8.9 hours per day), women who had shorter $(\leq 6.0$ hours per day) [OR (95\% CI): 1.53 (1.10-2.12)] and longer sleep duration ( $\geq 9.0$ hours per day) [OR (95\% CI): 1.59 (1.17-2.17)] had an increased risk of breast cancer. Night-shift work was associated with an increased risk of breast cancer [OR (95\% CI): 1.34 (1.05-1.72)]. In addition, daytime napping was associated with a reduced risk of breast cancer among night-shift workers [OR (95\% CI): 0.57 (0.36-0.90)], but no association was found among women who never had night-shift work. Night-shift work and longer sleep duration also synergistically increased breast cancer risk [OR (95\% CI): 3.69 (1.94-7.02)] (p for interaction $=0.009$ ). Sleep problems, including night-shift work, and shorter and longer sleep duration, are associated with an increased breast cancer risk. In particular, the combined effects of night-shift work with no daytime napping or longer sleep duration are greater than the independent effects.

\section{Prostate cancer}

Prostate cancer is one of the most common cancers in males with an increasing incidence worldwide [54]. The etiology of this hormone-dependent tumor seems multifactorial and remains largely unknown compared to other common cancers. Chronic sleep deprivation and night shift work have been suggested as possible risk factors for prostate cancer [55].

\section{Shif work and prostate cancer}

Epidemiological studies on shift work and prostate cancer risk 
are scarce and results are mixed. A meta-analysis including 2,459,845 individuals from eight studies published between 2006 and 2014 (three case-control studies and five cohorts) found a $24 \%$ increase in the risk of prostate cancer for night-shift workers (RR: 1.24, 95\% CI: 1.05-1.46; p=0.011) [56]. Dose-response subgroup analysis suggested that an increase in night-shift work of 5 years duration was significantly associated with a $2.8 \%$ (95\% CI: $0.3-5.4 \%$, $\mathrm{p}=0.030$ ) increase in the risk of prostate cancer.

A more recent French population-based case-control study [57], including 818 incident prostate cancer cases and 875 controls reported that overall, ever night work, either permanent or rotating, was not associated to prostate cancer. Similarly, a prospective cohort study of Finnish twins [58] including 11,370 men, over a median of 30 years of follow-up did not find any association neither with rotating shift work (HR: 1; 95\% CI: 0.70-1.20), nor with fixed night work (HR: 0.5; 95\% CI: 0.10-1.90). However, according to the dose-response analysis in the French study [57], a long duration of at least 20 years of permanent night work was associated with aggressive prostate cancer (OR: 1.76, 95\% CI: 1.13$2.75)$, even more pronounced in combination with a long shift length (>10 hours) or at least 6 consecutive nights (OR: 4.64, 95\% CI: 1.78-12.13; OR: 2.43, 95\% CI: 1.32-4.47, respectively).

\section{Sleep duration and prostate cancer}

In a population-based Swedish cohort study ( $n=14,041$ men), during 13 years of follow-up, Markt et al. [59] identified 785 cases of incident prostate cancer. Overall, $20 \%$ of men reported sleeping 8 hours per night, $4 \%$ reported sleeping 5 hours or fewer, and $2 \%$ reported 9 hours or more of sleep per night. Men at the extremes of sleep duration ( $\leq 5 \mathrm{~h}$ and $\geq 9 \mathrm{~h}$ ) were more likely to be retired and therefore have no working hours. In multivariableadjusted analyses, sleep duration was not associated with risk of prostate cancer. In addition, there were no association between prostate cancer and sleep disruption, as defined by difficulty falling asleep, difficulty maintaining sleep, sleep quality, and restorative power of sleep.

In contrast, two other studies indicate that, short night-time sleep may be associated with an increased risk of prostate cancer in non-shift working men. Within the prospective AGES-Reykjavik population-based cohort ( $n=2,102$ men), the association between sleep disruption and prostate cancer risk has been studied over a five-year time frame [60]. During follow-up, 135 men (6.4\%) were diagnosed with prostate cancer. Compared to men without sleep disruption, those with problems falling and staying asleep were at significantly increased risk of prostate cancer [HR, 1.7 (95\% CI: 1.0-2.9) and 2.1 (95\% CI: 1.2-3.7)], respectively, with increasing sleep disruption severity. In other words, men with insomnia were twice as likely to develop prostate cancer. In the Ohsaki Cohort Study [61], an inverse association between sleep duration and the risk of prostate cancer has been found among nonshift working Japanese men. Authors reported a decreased risk for those sleeping at least 9 hours per night. The HR of prostate cancer in short sleepers (those sleeping 6 hours or less) was 1.34
(95\% CI: 0.83-2.17) and the HR for long sleepers (those sleeping at least 9 hours) was 0.48 (95\% CI: $0.29-0.79$ ) ( $\mathrm{p}$ for trend=0.02).

\section{CANCER RISK MANAGEMENT IN THE CONTEXT OF CIRCADIAN SLEEP DISRUPTION}

In the globalizing world, many countries face to the growing demands in productivity in different industries such as energy production, transportation, health care, telecommunication and entertainment. Consequently, circadian sleep disruption related to modern life conditions including the night-time use of portable light-emitting devices (i.e., computer screens, tablets and cell phones) [62] and extended nocturnal business hours and night shift works are increasingly prevalent in the general population and even a modestly increased risk could lead to considerable numbers of breast and prostate cancer cases if there were a causal association.

While many factors and substances in living and working environments are known to be carcinogenic, others are suspected to be carcinogenic such as circadian sleep disruption [1]. In the area of risk management, it is important to distinguish prevention, which is the management of known and proven risks, from precaution, which corresponds to the management of uncertain risks. The precautionary principle is based on the use of public management of potentially serious and/or irreversible health risks, especially when there are significant uncertainties regarding the impact on the population. The precautionary principle is usually associated with the principle of proportionality, according to which the cost of the measures necessary to reduce the risk must not be disproportionate to the expected benefits. Thus, a number of precautionary measures may be proposed in order to reduce the possible impact of chronic circadian sleep disruption on the genesis of breast and prostate cancers. The years of night shifts can be limited for employees (i.e., less than 20 years), the duration of night shift working hours may be shortened. High number of consecutive night shifts may be avoided (i.e., fewer than 6 consecutive nights per month). Instead of permanent night work, rotating shifts may be proposed. Rest periods after night shifts may be lengthening. Finally, co-exposure to other occupational carcinogens additional to years of employment in non-day shift work may be controlled. In addition, melatonin with its oncostatic poperties may be of use in the precautionary measures and treatment of breast and prostate cancers [11].

\section{CONCLUSION}

This review illustrates the emerging evidence from human and animal studies that chronic circadian sleep disruption related to sleep deprivation and/or night shift work may be a significant risk factor for both breast and prostate cancers. The mechanistic hypotheses that the multilevel endocrine changes caused by circadian disruption with sleep deprivation and melatonin suppression 
through LAN may favor the induction and/or promotion of malignant tumors are likely [63]. Despite a large number of epidemiological studies suggesting that circadian sleep disruption due to night shift work may be associated with increased risk of both breast and prostate cancers, some other cohorts and meta-analyses did not find any associations. These conflicting results might be due to several methodological limitations. First, in available epidemiological studies there have not been clear and uniform definitions of 'shift work' and 'shift work exposure times' used [1]. Second, the majority of these studies did not take daytime napping into account [53] as well as the possible environmental carcinogenic factors associated to sleep deprivation and night shift work. Third, short-term follow-up of aging cohorts may explain why some cohort studies may have null findings [64]. Consequently, the need for high quality epidemiological cancer research still exists. In the future, epidemiological studies might be designed with more precise definitions of shift work, sleep deprivation and nocturnal light exposure. Genetic profiles (polymorphisms in circadian genes, clinical chronotypes), objective sleep patterns (actimetric and polysomnographic findings), other environmental and occupational carcinogenic factors and comorbidities can be integrated into analyses. Since the classification of shiftwork that involves circadian disruption as a 'probable human carcinogen' by the IARC, subjects who have worked 20 years or more in night shift work may need special attention for the screening and monitoring of breast and prostate cancers. Finally, based on the precautionary principle, at-risk subjects can be identified and moved away from shift work stations as early as possible before reaching several years of exposure. In order to limit the risk of cancer, this precautionary principle needs to be applied to public health actions as well as to actions pursued by policy makers, and industry.

\section{Acknowledgments}

None

\section{Conflicts of Interest}

The authors have no potential conflicts of interest to disclose.

\section{Author Contributions}

Conceptualization: S.-Hakki Onen, Fannie Onen. Methodology:

S.-Hakki Onen, Fannie Onen. Resources: S.-Hakki Onen, Fannie Onen. Writing-original draft: S.-Hakki Onen, Fannie Onen. Writing_review \& editing: S.-Hakki Onen, Fannie Onen.

\section{ORCID iD}

\section{S.-Hakki Onen}

https://orcid.org/0000-0002-1277-1027

\section{REFERENCES}

1. Stevens RG, Hansen J, Costa G, Haus E, Kauppinen T, Aronson KJ, et al. Considerations of circadian impact for defining 'shift work' in cancer studies: IARC Working Group Report. Occup Environ Med 2011;68:154-162.
2. IARC monographs on the identification of carcinogenic hazards to humans. Available at: https://monographs.iarc.fr/agents-classified-by-theiarc/. Accessed November 13, 2019.

3. Wise J. Danish night shift workers with breast cancer awarded compensation. BMJ 2009;338:b1152.

4. IARC Monographs Vol 124 group. Carcinogenicity of night shift work. Lancet Oncol 2019;20:1058-1059.

5. Brainard GC, Sliney D, Hanifin JP, Glickman G, Byrne B, Greeson JM, et al. Sensitivity of the human circadian system to short-wavelength $(420-\mathrm{nm})$ light. J Biol Rhythms 2008;23:379-386.

6. Haus E, Smolensky M. Biological clocks and shift work: circadian dysregulation and potential long-term effects. Cancer Causes Control 2006;17:489500 .

7. Zhu Y, Brown HN, Zhang Y, Stevens RG, Zheng T. Period3 structural variation: a circadian biomarker associated with breast cancer in young women. Cancer Epidemiol Biomarkers Prev 2005;14:268-270.

8. Zhu Y, Stevens RG, Leaderer D, Hoffman A, Holford T, Zhang Y, et al. Non-synonymous polymorphisms in the circadian gene NPAS2 and breast cancer risk. Breast Cancer Res Treat 2008;107:421-425.

9. Chu LW, Zhu Y, Yu K, Zheng T, Yu H, Zhang Y, et al. Variants in circadian genes and prostate cancer risk: a population-based study in China. Prostate Cancer Prostatic Dis 2008;11:342-348.

10. Zhu Y, Leaderer D, Guss C, Brown HN, Zhang Y, Boyle P, et al. Ala394Thr polymorphism in the clock gene NPAS2: a circadian modifier for the risk of non-Hodgkin's lymphoma. Int J Cancer 2007;120:432-435.

11. Li Y, Li S, Zhou Y, Meng X, Zhang JJ, Xu DP, et al. Melatonin for the prevention and treatment of cancer. Oncotarget 2017;8:39896-39921.

12. Cos S, Sánchez-Barceló EJ. Melatonin and mammary pathological growth. Front Neuroendocrinol 2000;21:133-170.

13. Sánchez-Barceló EJ, Cos S, Fernández R, Mediavilla MD. Melatonin and mammary cancer: a short review. Endocr Relat Cancer 2003;10:153-159.

14. Debeljuk L, Feder VM, Paulucci OA. Effects of melatonin on changes induced by castration and testosterone in sexual structures of male rats. Endocrinology 1970;87:1358-1360.

15. Allegra M, Reiter RJ, Tan DX, Gentile C, Tesoriere L, Livrea MA. The chemistry of melatonin's interaction with reactive species. J Pineal Res 2003;34:1-10.

16. Rodriguez C, Mayo JC, Sainz RM, Antolín I, Herrera F, Martín V, et al. Regulation of antioxidant enzymes: a significant role for melatonin. J Pineal Res 2004;36:1-9.

17. Liu R, Fu A, Hoffman AE, Zheng T, Zhu Y. Melatonin enhances DNA repair capacity possibly by affecting genes involved in DNA damage responsive pathways. BMC Cell Biol 2013;14:1.

18. Clow A, Hucklebridge F, Stalder T, Evans P, Thorn L. The cortisol awakening response: more than a measure of HPA axis function. Neurosci Biobehav Rev 2010;35:97-103.

19. Charles LE, Fekedulegn D, Burchfiel CM, Hartley TA, Andrew ME, Violanti JM, et al. Shiftwork and diurnal salivary cortisol patterns among police officers. J Occup Environ Med 2016;58:542-549.

20. Mormont MC, Lévi F. Circadian-system alterations during cancer processes: a review. Int J Cancer 1997;70:241-247.

21. Sephton S, Spiegel D. Circadian disruption in cancer: a neuroendocrineimmune pathway from stress to disease? Brain Behav Immun 2003;17:321328.

22. Sephton SE, Sapolsky RM, Kraemer HC, Spiegel D. Diurnal cortisol rhythm as a predictor of breast cancer survival. J Natl Cancer Inst 2000;92: 994-1000.

23. Williams G. Aromatase up-regulation, insulin and raised intracellular oestrogens in men, induce adiposity, metabolic syndrome and prostate disease, via aberrant ER- $\alpha$ and GPER signalling. Mol Cell Endocrinol 2012;351: 269-278.

24. Simpson ER. Biology of aromatase in the mammary gland. J Mammary Gland Biol Neoplasia 2000;5:251-258.

25. Brodie A, Lu Q, Nakamura J. Aromatase in the normal breast and breast cancer. J Steroid Biochem Mol Biol 1997;61:281-286.

26. Fabre B, Grosman H, Gonzalez D, Machulsky NF, Repetto EM, Mesch V, et al. Prostate cancer, high cortisol levels and complex hormonal interaction. Asian Pac J Cancer Prev 2016;17:3167-3171.

27. Bray F, McCarron P, Parkin DM. The changing global patterns of female 
breast cancer incidence and mortality. Breast Cancer Res 2004;6:229-239.

28. Rojas K, Stuckey A. Breast cancer epidemiology and risk factors. Clin Obstet Gynecol 2016;59:651-672.

29. Ziegler RG, Hoover RN, Pike MC, Hildesheim A, Nomura AM, West DW, et al. Migration patterns and breast cancer risk in Asian-American women. J Natl Cancer Inst 1993;85:1819-1827.

30. Menck HR. Cancer incidence in the Mexican American. Natl Cancer Inst Monogr 1977;47:103-106.

31. Thomas DB, Karagas MR. Migrant studies. In: Schottenfeld D, Fraumeni JFJr, editors. Cancer epidemiology and prevention. 2nd ed. New York: Oxford University Press, 1996, p. 236-254

32. Parkin DM, Khlat M. Studies of cancer in migrants: rationale and methodology. Eur J Cancer 1996;32A:761-771.

33. McCredie M. Cancer epidemiology in migrant populations. Recent Results Cancer Res 1998;154:298-305.

34. Schernhammer ES, Laden F, Speizer FE, Willett WC, Hunter DJ, Kawachi I, et al. Rotating night shifts and risk of breast cancer in women participating in the Nurses Health Study. J Natl Cancer Inst 2001;93:1563-1568.

35. Schernhammer ES, Kroenke CH, Laden F, Hankinson SE. Night work and risk of breast cancer. Epidemiology 2006;17:108-111.

36. Hansen J, Stevens RG. Case-control study of shift-work and breast cancer risk in Danish nurses: impact of shift systems. Eur J Cancer 2012;48:17221729.

37. Lie JA, Kjuus H, Zienolddiny S, Haugen A, Stevens RG, Kjærheim K. Night work and breast cancer risk among Norwegian nurses: assessment by different exposure metrics. Am J Epidemiol 2011;173:1272-1279.

38. Menegaux F, Truong T, Anger A, Cordina-Duverger E, Lamkarkach F, Arveux P, et al. Night work and breast cancer: a population-based casecontrol study in France (the CECILE study). Int J Cancer 2013;132:924-931.

39. Fritschi L, Erren TC, Glass DC, Girschik J, Thomson AK, Saunders C, et al. The association between different night shiftwork factors and breast cancer: a case-control study. Br J Cancer 2013;109:2472-2480.

40. Jones ME, Schoemaker MJ, McFadden EC, Wright LB, Johns LE, Swerdlow AJ. Night shift work and risk of breast cancer in women: the Generations Study cohort. Br J Cancer 2019;121:172-179.

41. Travis RC, Balkwill A, Fensom GK, Appleby PN, Reeves GK, Wang XS, et al. Night shift work and breast cancer incidence: three prospective studies and meta-analysis of published studies. J Natl Cancer Inst 2016;108:djw169.

42. McElvenny DM, Crawford JO, Cherrie JW. What should we tell shift workers to do to reduce their cancer risk? Occup Med (Lond) 2018;68:5-7.

43. Kloog I, Portnov BA, Rennert HS, Haim A. Does the modern urbanized sleeping habitat pose a breast cancer risk? Chronobiol Int 2011;28:76-80.

44. Kakizaki M, Kuriyama S, Sone T, Ohmori-Matsuda K, Hozawa A, Nakaya $\mathrm{N}$, et al. Sleep duration and the risk of breast cancer: the Ohsaki Cohort Study. Br J Cancer 2008;99:1502-1505.

45. Xiao Q, Signorello LB, Brinton LA, Cohen SS, Blot WJ, Matthews CE. Sleep duration and breast cancer risk among black and white women. Sleep Med 2016;20:25-29.

46. Thompson CL, Li L. Association of sleep duration and breast cancer OncotypeDX recurrence score. Breast Cancer Res Treat 2012;134:1291-1295.

47. Verkasalo PK, Lillberg K, Stevens RG, Hublin C, Partinen M, Koskenvuo $\mathrm{M}$, et al. Sleep duration and breast cancer: a prospective cohort study. Cancer Res 2005;65:9595-9600.
48. Wu AH, Wang R, Koh WP, Stanczyk FZ, Lee HP, Yu MC. Sleep duration, melatonin and breast cancer among Chinese women in Singapore. Carcinogenesis 2008;29:1244-1248.

49. McElroy JA, Newcomb PA, Titus-Ernstoff L, Trentham-Dietz A, Hampton JM, Egan KM. Duration of sleep and breast cancer risk in a large population-based case-control study. J Sleep Res 2006;15:241-249.

50. Lu C, Sun H, Huang J, Yin S, Hou W, Zhang J, et al. Long-term sleep duration as a risk factor for breast cancer: evidence from a systematic review and dose-response meta-analysis. Biomed Res Int 2017;2017:4845059.

51. Vogtmann E, Levitan EB, Hale L, Shikany JM, Shah NA, Endeshaw Y, et al. Association between sleep and breast cancer incidence among postmenopausal women in the Women's Health Initiative. Sleep 2013;36:1437-1444.

52. Pinheiro SP, Schernhammer ES, Tworoger SS, Michels KB. A prospective study on habitual duration of sleep and incidence of breast cancer in a large cohort of women. Cancer Res 2006;66:5521-5525.

53. Wang P, Ren FM, Lin Y, Su FX, Jia WH, Su XF, et al. Night-shift work, sleep duration, daytime napping, and breast cancer risk. Sleep Med 2015;16:462468.

54. Bray F, Ferlay J, Soerjomataram I, Siegel RL, Torre LA, Jemal A. Global cancer statistics 2018: GLOBOCAN estimates of incidence and mortality worldwide for 36 cancers in 185 countries. CA Cancer J Clin 2018;68:394424.

55. Sigurdardottir LG, Valdimarsdottir UA, Fall K, Rider JR, Lockley SW, Schernhammer E, et al. Circadian disruption, sleep loss, and prostate cancer risk: a systematic review of epidemiologic studies. Cancer Epidemiol Biomarkers Prev 2012;21:1002-1011.

56. Rao D, Yu H, Bai Y, Zheng X, Xie L. Does night-shift work increase the risk of prostate cancer? A systematic review and meta-analysis. Onco Targets Ther 2015;8:2817-2826.

57. Wendeu-Foyet MG, Bayon V, Cénée S, Trétarre B, Rébillard X, Cancel-Tassin G, et al. Night work and prostate cancer risk: results from the EPICAP Study. Occup Environ Med 2018;75:573-581.

58. Dickerman BA, Markt SC, Koskenvuo M, Hublin C, Pukkala E, Mucci LA, et al. Sleep disruption, chronotype, shift work, and prostate cancer risk and mortality: a 30-year prospective cohort study of Finnish twins. Cancer Causes Control 2016;27:1361-1370.

59. Markt SC, Grotta A, Nyren O, Adami HO, Mucci LA, Valdimarsdottir UA, et al. Insufficient sleep and risk of prostate cancer in a large Swedish cohort. Sleep 2015;38:1405-1410.

60. Sigurdardottir LG, Valdimarsdottir UA, Mucci LA, Fall K, Rider JR, Schernhammer E, et al. Sleep disruption among older men and risk of prostate cancer. Cancer Epidemiol Biomarkers Prev 2013;22:872-879.

61. Kakizaki M, Inoue K, Kuriyama S, Sone T, Matsuda-Ohmori K, Nakaya N, et al. Sleep duration and the risk of prostate cancer: the Ohsaki Cohort Study. Br J Cancer 2008;99:176-178.

62. Chang AM, Aeschbach D, Duffy JF, Czeisler CA. Evening use of lightemitting eReaders negatively affects sleep, circadian timing, and nextmorning alertness. Proc Natl Acad Sci U S A 2015;112:1232-1237.

63. Costa G, Haus E, Stevens R. Shift work and cancer-considerations on rationale, mechanisms, and epidemiology. Scand J Work Environ Health 2010;36:163-179.

64. Hansen J. Night shift work and risk of breast cancer. Curr Environ Health Rep 2017;4:325-339. 